Research Article

\title{
Nephropathy among type II diabetes at a rural health centre, Goa, India
}

\author{
Nadia Rangel Pinto*, Mohan Vinoth, Umesh Kamat, Agnelo Ferreira, Frederick Vaz
}

Department of Preventive and Social Medicine, Goa Medical College, Bambolim, Goa 403202, India

Received: 12 October 2015

Revised: 11 January 2016

Accepted: 20 January 2016

\section{*Correspondence:}

Dr. Nadia Rangel Pinto,

E-mail: nadiarpinto@gmail.com

Copyright: ( $)$ the author(s), publisher and licensee Medip Academy. This is an open-access article distributed under the terms of the Creative Commons Attribution Non-Commercial License, which permits unrestricted non-commercial use, distribution, and reproduction in any medium, provided the original work is properly cited.

\begin{abstract}
Background: Diabetes mellitus and chronic kidney disease is a dreadful combination. India has the world's largest population suffering from diabetes mellitus and is predicted to rise to almost 70 million by the year 2025 which would make India vulnerable to complications like diabetic nephropathy leading to end stage renal disease. The study was conducted at a rural health centre with the aim to study and assess Type II diabetes mellitus for nephropathy.

Methods: A case series study comprising 241 Type II diabetes mellitus patients above 18 years of age on treatment were included. Patients with UACR equal to or above $30-\mu \mathrm{g} / \mathrm{mg}$ creatinine were subjected to ophthalmoscopy to detect Retinopathy. Microalbuminuria with retinopathy is diagnostic of nephropathy. Further, with serum creatinine, estimated glomerular filtration rate (eGFR) was calculated using cockcraft gault equation and nephropathy was graded as per NKF- KDOQI “clinical guidelines for CKD”, Statistical analysis was done using SPSS version 22. Fisher's exact and Student 't' tests were used.

Results: Out of total 241 subjects, 49 i.e. $20.3 \%$ were found to have microalbuminuria. Forty -two patients i.e. $17.4 \%$ had retinopathy with microalbuminuria hence prevalence of diabetic nephropathy in this study was $17.4 \%$. Correlates including older age, duration of diabetes, tobacco smoking, hazardous drinking, missed medication, serum creatinine and $\mathrm{HbA} 1 \mathrm{c}$ levels were found to be significantly associated with nephropathy. Fifty percent of the diabetic nephropathy patients had Grade III Nephropathy, while $42.8 \%$ had Grade II and $7.14 \%$ Grade I.

Conclusions: Effective screening programme at primary care level can help detect nephropathy early, delay progression to end stage renal disease (ESRD) and reduce cardiovascular mortality.
\end{abstract}

Keywords: Diabetes mellitus, Microalbuminuria, Nephropathy, Correlates

\section{INTRODUCTION}

Diabetes Mellitus and Chronic Kidney Disease (CKD) is a dreadful combination. India has the world's largest population suffering from Diabetes Mellitus and is particularly frequent in rural populations of India. ${ }^{1-4}$ According to the Diabetes Atlas, it is predicted to rise to almost 70 million by the year 2025 which also makes India vulnerable to complications like diabetic nephropathy leading to end stage renal disease. ${ }^{5,6}$
The Indian CKD Registry has made pertinent observations that Diabetes Mellitus is the cause of CKD in $31.2 \%$ patients. As CKD progresses cardiovascular disease is more commonly encountered with $0.7 \%$ at stage 1 to $48.5 \%$ at stage $\mathrm{V}$.

Microalbuminuria is diagnosed at urinary albumin creatinine ratio (UACR) between 30 and $300 \mu \mathrm{g} / \mathrm{mg}$ (National Kidney Foundation, 2007). Microalbuminuria is present when there is not yet evidence of abnormal 
glomerular filtration. Thus, in diabetes mellitus, microalbuminuria is an early marker of the subsequent development of diabetic nephropathy.

Correlates including age, duration of diabetes mellitus, history of missed medication at least once a week, alcohol and tobacco consumption, HbA1c and Serum creatinine are associated with nephropathy in diabetic patients.

Diabetic kidney disease burdens dialysis centers while $\mathrm{CKD}$ is also an independent risk factor for cardiovascular disease (CVD). Microalbuminuria confers $50 \%$ risk to CVD while macroalbuminuria raises the risk of CVD by $350 \%$ and for these reasons the International Society of Nephrology has considered CKD, a public health problem.

Studies have shown the prevalence of Diabetes in Urban India is about $14.3 \% .^{7}$ while it is $13.5 \%$ in rural areas of India. ${ }^{8}$ Seven percent of Diabetics have microalbuminuria at the time of diagnosis. ${ }^{9}$ Tertiary kidney care is not easily accessible to rural patients. Early diagnosis is critical to ensure quality of life. Hence the present study on nephropathy and its correlates was conducted among Type II diabetes mellitus patients at a rural health centre in Goa, India.

\section{METHODS}

This study was an Outpatient department based case series study conducted over a period of four months from January to April 2013 at the rural health centre attached to Goa Medical College, Goa, India. All patients of Type II diabetes mellitus 18 years and above availing treatment from the rural health centre were included in the study. The total number of patients included in the study was 241.

After informed consent, data was collected on age, duration of diabetes, tobacco and hazardous drinking habits, adherence to medication, HbA1c (glycosylated haemoglobin) and serum creatinine. To assess the microalbumin in urine, the patients were subjected to urine albumin creatinine ratio (UACR) using early morning urine sample as per American diabetic association criteria. The patients with UACR $30 \mu \mathrm{g} / \mathrm{mg}$ creatinine or more were subjected to fundus examination by ophthalmoscopy to detect retinopathy.

UACR of $30 \mu \mathrm{g} / \mathrm{mg}$ creatinine or more is defined as positive for microalbuminuria (National kidney foundation- kidney Disease outcome quality initiative guidelines).

Fundus examination was done using Heinz ophthalmoscope following full mydriasis. Early diagnosis and treatment of retinopathy study (EDTRS) classification was used to diagnose retinopathy.
Patients with positive microalbuminuria and retinopathy were labelled as diabetic nephropathy. Further with serum creatinine, estimated glomerular filtration rate (eGFR) was calculated using Cockcraft Gault equation and nephropathy was graded. ${ }^{10}$

Data is expressed in means and proportion. Statistical analysis is done using SPSS Version 22. Student $t$ test and Fisher's exact test were used. Approval of the Institutional Ethics committee was obtained on 08/10/2012.

\section{RESULTS}

A total of 241 type II diabetes mellitus patients above the age of 18 years attending treatment at a rural health centre participated in this study. The mean age of the patients was 58.81 years $(\mathrm{S} . \mathrm{D}=10.53)$. Mean duration of diabetes mellitus was 6.97 years $(\mathrm{SD}=6.21) .63 .5 \%$ belonged to the 50 to 69 year age group. $16.2 \%$ were between 40-49 years and $15.3 \%$ were between $70-79$ years. Only $2.9 \%$ were aged between $30-39$ years and $2.1 \%$ were above 80 years of age. There were no patients below 30 years of age.

Out of total 241 patients, 49 i.e. $20.3 \%$ were found to have microalbuminuria. Of these 49 , forty-two patients $(17.4 \%)$ had microalbuminuria with retinopathy hence prevalence of diabetic nephropathy in this study was $17.4 \%$.

Patients having history of missed medication more than once a week were found to be $17.4 \%$. Among them, $45.2 \%$ had diabetic nephropathy whereas only $11.6 \%$ patients without history of missed medication had nephropathy $(\mathrm{p}=0.0001$; Table 1$)$.

Of the total 241 patients, $14.1 \%$ were hazardous drinkers; $47.05 \%$ of hazardous drinkers had nephropathy while only $12.56 \%$ of non-hazardous drinkers had nephropathy $(\mathrm{p}=0.0001 ;$ Table 1$)$.

Among the study patients there were $12.04 \%$ current tobacco users, $8.28 \%$ former tobacco users and $79.68 \%$ non-tobacco users. Among them, diabetic nephropathy was present in $68.9 \%$ (highest among current smokers), $40 \%$ and $7.2 \%$ (lowest among non-smokers) respectively ( $\mathrm{p}=0.0001 ;$ Table 1).

The mean HbA1c level among the patients with diabetic nephropathy was $8.15 \%(\mathrm{~S} . \mathrm{D}=1.32)$ while in patients without nephropathy was $6.83 \% \quad(\mathrm{~S} . \mathrm{D}=0.86)$. The association is statistically significant ( $\mathrm{p}=0.0001$; Table 1$)$. The mean creatinine among patients with nephropathy was $0.93 \mathrm{mg} / \mathrm{dl}$ (higher) $(\mathrm{SD}=0.24)$ while in those without nephropathy was $0.78 \mathrm{mg} / \mathrm{dl}$ (lower) $(\mathrm{SD}=0.18)$ (Table 1 ; $\mathrm{p}=0.0001)$. 
Majority of the nephropathy patients i.e., $50 \%$ were at grade III, $42.86 \%$ were at grade II while $7.14 \%$ were at grade I. There were no patients with grade IV and grade V.

Table 1: Variables associated with nephropathy in type II diabetes mellitus.

\begin{tabular}{|c|c|c|c|c|}
\hline Variable & $\begin{array}{l}\text { Diabetic nephropathy } \\
\text { present }\end{array}$ & $\begin{array}{l}\text { Diabetic nephropathy } \\
\text { absent }\end{array}$ & Test of significance & p value \\
\hline \multicolumn{5}{|l|}{ Gender } \\
\hline Male & $17(18.3)$ & $76(81.7)$ & & \\
\hline Female & 25 (16.9) & $123(83.1)$ & & \\
\hline Total & $42(17.4)$ & 199 (82.6) & Fisher exact & 0.861 \\
\hline \multicolumn{5}{|l|}{ Missed medication } \\
\hline Present & $19(45.2)$ & $23(54.8)$ & & \\
\hline Absent & $23(11.6)$ & $176(88.4)$ & & \\
\hline Total & $42(17.4)$ & $199(82.6)$ & Fisher exact & 0.0001 \\
\hline \multicolumn{5}{|l|}{ Alcohol } \\
\hline Hazardous drinkers & $16(47.05)$ & $18(52.95)$ & & \\
\hline $\begin{array}{l}\text { Non-hazardous } \\
\text { drinkers }\end{array}$ & $26(12.56)$ & $181(87.44)$ & & \\
\hline Total & $42(17.4)$ & $199(82.6)$ & Fisher exact & 0.0001 \\
\hline \multicolumn{5}{|l|}{ Tobacco } \\
\hline Current user & $20(68.9)$ & $9(31.1)$ & & \\
\hline Former user & $8(40)$ & $12(60)$ & & \\
\hline Non-user & $14(7.2)$ & $178(92.8)$ & & \\
\hline Total & $42(17.4)$ & $199(82.6)$ & Fisher exact & 0.0001 \\
\hline Mean Age (years) & $66.7 \pm 8.62$ & $57.28 \pm 10.2$ & $\mathrm{t}$ test & 0.0001 \\
\hline $\begin{array}{l}\text { Mean Duration of } \\
\text { Diabetes (years) }\end{array}$ & $13.9 \pm 7.67$ & $5.5 \pm 4.72$ & $\mathrm{t}$ test & 0.0001 \\
\hline Mean HbA1c & $8.15 \pm 1.32$ & $6.83 \pm 0.86$ & $\mathrm{t}$ test & 0.0001 \\
\hline $\begin{array}{l}\text { Mean Serum } \\
\text { creatinine }\end{array}$ & $0.93 \pm 0.24$ & $0.78 \pm 0.18$ & $\mathrm{t}$ test & 0.0001 \\
\hline
\end{tabular}

\section{DISCUSSION}

The prevalence of diabetic nephropathy was found to be $17.4 \%$. It was higher than the prevalence seen in another study among Asians in India (8.9\%) but lower than that seen among Asians in UK was $22.3 \% .^{11}$ This could indicate the rising prevalence in India and an opportune time to reverse the trend. Besides change in geographical environment can further increase the risk as observed in the above study in UK. Older age and longer duration of diabetes were significantly associated with nephropathy.

Missed medication, hazardous drinking, and current smoking among diabetics indicated significant association with diabetic nephropathy. There is obvious evidence from other research too that those diabetics with difficulty adhering to treatment regimens have less than optimal management and control of illness. ${ }^{12}$ Almost half of all those with history of hazardous drinking had nephropathy. ${ }^{13}$ Heavy alcohol consumption is known to be associated with CKD. ${ }^{14}$ Microalbuminuria was found to be higher in smokers than in non-smokers with type II diabetes mellitus in a population based cohort. ${ }^{15}$ Ensuring compliance to medication and prevention of hazardous drinking and tobacco smoking needs to be focused on in preventive programs.

Since HbA1c levels are significantly associated with nephropathy, reducing $\mathrm{HbA} 1 \mathrm{c}$ to stable levels ensures good control of diabetes and thereby prevention of nephropathy. Atherosclerosis risk in communities (ARIC) study also found that HbA1c is a powerful predictor of diabetic nephropathy. ${ }^{16}$ Raised creatinine levels were also significantly associated with nephropathy and should be monitored.

Most of the nephropathy was found to have grade II and grade III nephropathy measures can be taken to prevent their progress to end stage renal disease while no grade $\mathrm{IV}$ and $\mathrm{V}$ disease could be due to survival bias. It is imperative to screen even patients in rural areas for microalbuminuria at the time of diagnosis and initiation of treatment with annual screening for microalbuminuria to detect early nephropathy. 


\section{CONCLUSION}

Incorporating this approach in screening programs in addition to prevention of other known risk factors of nephropathy will tremendously benefit the rural population of India to detect nephropathy early, delay progression to end stage renal disease and reduce cardiovascular mortality.

Funding: No funding sources Conflict of interest: None declared

Ethical approval: The study was approved by the Institutional Ethics Committee

\section{REFERENCES}

1. Bethesda MD. United States Renal Data Resource Systems (USRDS) - Annual data report. National Institute of Diabetes \& Digestive \& Kidney Diseases, National Institute of Health, US Department of Health and human services, 2007.

2. Deepa M, Pradeepa R, Rema M, Mohan A, Deepa R, Shanthirani S. et al. The Chennai Urban Rural Epidemiology study (CURES) - study design and methodology (Urban component) CURES. J Assoc Physicians India. 2003;51:863-70.

3. Abdul FB. Type II Diabetes and Rural India. Lancet. 2007;369:273-4.

4. Gupta SK, Singh Z, Purty AJ, Kar M, Vedapriya D, Mahajan $\mathrm{P}$, et al. Diabetes prevalence and its risk factors in rural area of Tamil Nadu. Indian J Community Med. 2010;35:396-9.

5. Rajapurkar M, Dabhi M. Burden of disease prevalence and incidence of renal disease in India. Clin Nephrol. 2010;74 Suppl 1:S9-12.

6. Seventh report of the Joint national Committee on Prevention, Detection, Evaluation and treatment of high blood pressure Hypertension. 2003;42:1206.
7. Mohan V, Sandeep S, Deepa R, Shah B, Varghese C. Epidemiology of Type 2 Diabetes: Indian scenario. Indian J med res. 2007;125:217-30.

8. Chow CK, Krishnam Raju P, Rama Raju, Reddy KS. The prevalence and management of Diabetes in Rural India. Diabetes care. 2006;29(7):1717-8.

9. American Diabetes Association: Nephropathy in Diabetes (position Statement) Diabetes Care. 2004;27(suppl.1):S79-83.

10. KDIGO 2012 Clinical practice guidelines for the evaluation and management of chronic kidney disease. 2013;3(1).

11. Verghese T. Diabetic nephropathy- Indian perspective. The Lancet. 2011;3:771-9.

12. World Health Organization booklet on Adherence, 2003.

13. WHO 2001.Alcohol use disorders identification test, 10 item instrument.

14. White SL, Polkinghorne KR, Cass A, Shaw JE, Atkins RC, Chadban SJ. Alcohol consumption and 5-year onset of chronic kidney disease: the AusDiab study. Nephrol Dial Transplant. 2009;24(8):246472.

15. Stephen R. Smoking and Kidney. Orth J am soc nephrol. 2002;13:1663-72.

16. Bash D, Selvin E, Steffes M, Coresh J, Astor BC. Poor glycemic control in diabetes and the risk of incident chronic kidney disease even in the absence of albuminuria and retinopathy: Atherosclerosis risk in communities (ARIC) Study. Arch Intern Med. 2008;168:2440-7.

Cite this article as: Pinto NR, Vinoth M, Kamat U, Ferreira A, Vaz F. Nephropathy among type II diabetes at a rural health centre, Goa, India. Int J Community Med Public Health 2016;3:555-8. 